\title{
1 Bacterial cellulose for increasing barrier 2 properties of paper products
}

3

4 Amanda Fillat ${ }^{\mathrm{a}}$ (0000-0003-0453-1178), Josefina Martínez ${ }^{\mathrm{a}}$ (0000-0002-2411-8188),

5 Cristina Valls ${ }^{\mathrm{b}}$ (0000-0003-2307-1779), Oriol Cusola ${ }^{\mathrm{b}}$ (0000-0002-1407-8285), M.

6 Blanca Roncero ${ }^{b^{*}}(0000-0002-2694-2368)$, Teresa Vidal ${ }^{\mathrm{b}}$ (0000-0001-6269-4114),

7 Susana V. Valenzuela ${ }^{a}$ (0000-0002-1684-9514), Pilar Diaz ${ }^{a}$ (0000-0003-4008-0669),

8 F.I. Javier Pastor ${ }^{\mathrm{a}^{*}}(0000-0003-0326-2527)$

9

$10{ }^{a}$ Department of Genetics, Microbiology and Statistics. Faculty of Biology. University of 11 Barcelona. Av. Diagonal 643, 08028 Barcelona, Spain

$12{ }^{b}$ CELBIOTECH_Paper Engineering Research Group. Universitat Politècnica de 13 Catalunya. BarcelonaTech. 08222 - Terrassa. Spain

15 *Authors for correspondence: F.I.J Pastor, E-mail: fpastor@ub.edu . Tel.: +34-93-4034626. Fax: +34-93164034629 and M. Blanca Roncero, E-mail: blanca.roncero@upc.edu . Tel.: +34-93-7398210. Fax: $17+34937398101$ 


\section{ABSTRACT}

Bacterial cellulose was combined with wood cellulose papers in order to obtain biomaterials with increased barrier properties. For this purpose, different parameters were assessed: two producing bacterial strains (Komagataeibacter xylinus and Gluconacetobacter sucrofermentans), two paper supports to hold bacterial cellulose (filter paper and eucalyptus paper), two kinds of combined biomaterials (composite and bilayer) and two drying temperatures $\left(90^{\circ} \mathrm{C}\right.$ and room temperature). Papers with increased barrier properties $\left(100^{\circ}\right.$ of water contact angle, 1220s of water drop test and air permeability $\left.<1 \mu \mathrm{m}(\mathrm{Pa} \cdot \mathrm{s})^{-1}\right)$ were obtained by the addition of bacterial cellulose to each paper support. However, due to the lower initial barrier properties of filter paper, higher improvements were produced with this paper. In addition, bacterial cellulose provided smoother surfaces with higher gloss without a detrimental effect on physical properties. Higher resistance to water absorption was obtained with K. xylinus possibly explained by its longer size fibers than G. sucrofermentans, as analysed by SEM. Smoothness and gloss were specially increased in the bilayer biomaterial although resistance to air and water were further improved in the composite. In this biomaterial drying at high temperature had a detrimental effect. SEM analysis of the products obtained showed the intimate contact among fibers of bacterial cellulose and wood paper. Results obtained show the contribution of bacterial cellulose to improve the properties of paper and its potential for the design of new added value paper products

39 from biomass.

Keywords: bacterial cellulose, barrier properties, hydrophobicity, air permeability, water resistance, cellulose paper 
Cellulose is the most abundant polymer of the Earth as a main component of plant biomass. Due to its availability, it has been traditionally used as a raw material for the production of a great diversity of industrial products including, paper, cardboard, textiles, food additives and pharmaceutical products, among others. The renewed interest for biomass valorization has fostered the research for the transformation and modification of plant residues into increased value products as biofuels and biomaterials, such as nanocellulose (Tuck et al. 2012; Beltramino et al. 2015, 2016). One of the main problems found is the intimate association of cellulose with lignin and hemicelluloses in plant biomass, in lignocellulose (Gilbert 2010). Deconstruction of plant cell wall requires the development of technology to improve the separation and upgrading of its lignocellulosic components in valuable new products (Gilbert 2010; Quintana et al. 2013, 2015). Besides plants, some microorganisms can also produce cellulose. Bacterial cellulose shows identical molecular composition to plant cellulose, but it shows a major advantage: it is not associated to lignin and hemicellulose, it is a high purity polymer.

Comparison of plant and bacterial cellulose show several properties that are favorably increased in bacterial cellulose, among which degree of polymerization and crystallinity, that are remarkably high (Klemm et al. 2005). An important property of bacterial cellulose is biocompatibility, that together with its elevated mechanical strength has prompted its use in medical applications such as scaffold for tissue and skin regeneration, artificial blood vessels, and as thickening food additive (Lin et al. 2013). These applications are correlated to its high water holding capacity determined by a structure of well separated cellulose nanofibrils, what makes bacterial cellulose a highly porous material that can show up to more than $90 \%$ water content. However, this water holding property is notably diminished after air drying, probably as a consequence of the hydrogen-bond formation among cellulose fibrils (Klemm et al. 2005; Hagiwara et al. 2010).

Mechanical properties of bacterial cellulose makes it an excellent candidate for the restoration of damaged paper documents where its surface lining does not affect 
80

cellulose as a reinforcing agent of pulps in papermaking has also been studied showing variable results depending on the pulp source (Yamanaka et al. 1989; Pommet et al. 2008; Gao et al. 2010; Tang et al. 2013; Xiang et al. 2017b), while its application for the production of nanocomposites can give a diversity of high added value products such as electronic and magnetic papers (Chawla et al. 2009; Shah et al. 2013; Lim et al. 2016).

On the other hand, barrier properties in papers (impermeability to air, water, water vapor, oxygen, fats, microorganisms, etc.), that are especially important in the food packaging sector, are currently provided by plastic films produced from petrochemical products. However, due to the increase in social awareness regarding the harmful environmental impact and the unsustainable life cycle of these materials, research is focusing on the creation of new biomaterials from renewable resources, which besides having these advanced barrier properties, may even become biodegradable (Cusola et al. 2014). Bacterial cellulose, because of its specific properties, can fulfil these requirements (Klemm et al. 2011; Osong et al. 2016). In fact, previous works have demonstrated bacterial cellulose can decrease wettability and permeability of paper (Gao et al. 2010; Santos et al. 2017; Xiang et al. 2017b).

The main purpose of this work was to combine bacterial cellulose with wood cellulose in order to increase barrier properties of paper without a detrimental effect on mechanical properties. Different aspects were taken into account, such as the microbial strain, the paper type and the way of joining bacterial cellulose and paper. For this purpose, bacterial cellulose produced by two different microbial strains was firstly characterized. Then, the bacterial cellulose was combined with two wood paper types to obtain two kind of biomaterials: composites or bilayers. In the composites, bacterial cellulose was directly synthesized by the growth of the producing bacteria on the surface of filter or eucalyptus paper sheets. In the bilayers, bacterial cellulose films were previously synthesized and then coated over the surface of the paper sheets. The properties of the resulting paper products were analyzed in terms of their mechanical strength, optical and barrier properties, and SEM morphology. 


\section{Bacterial strains}

Strains Komagataeibacter xylinus (DMS-2004) and Gluconacetobacter sucrofermentans (CECT 7291) were obtained from the DSMZ German Collection of

112 Microorganisms and Cell Cultures and from the Spanish Type Culture Collection,

113 respectively. They were grown in Hestrin-Schramm (HS) solid medium (Hestrin 1954)

114 in agar plates for maintenance. Suspensions of bacterial cells were obtained by gentle

115 shaking and inoculated in flasks containing $100 \mathrm{~mL}$ of HS liquid medium which were

116 incubated under static conditions for 4-7 days. Following, the surface bacterial films

117 produced were cut in small pieces $(1 \times 1 \mathrm{~cm})$ in sterile conditions and shaken in HS

118 liquid medium at $700 \mathrm{rpm}$ for $30 \mathrm{~min}$ to detach cells from the cellulose films. The

119 suspensions obtained were filtered through a gauze to remove film portions, centrifuged

120 at $4000 \mathrm{rpm}$ for $10 \mathrm{~min}$ and, after discarding supernatants, pellets were resuspended in

121 Ringer's solution $1 / 4\left(\mathrm{NaCl} 2.5 \mathrm{~g} \mathrm{~L}^{-1} ; \mathrm{KCl}, 0.105 \mathrm{~g} \mathrm{~L}^{-1} ; \mathrm{CaCl}_{2} \cdot 2 \mathrm{H}_{2} \mathrm{O}, 0.120 \mathrm{~g} \mathrm{~L}^{-1}\right.$; and

$\left.122 \mathrm{NaHCO}_{3}, 0.05 \mathrm{~g} \mathrm{~L}^{-1}\right)$. Optical density of the bacterial suspensions was adjusted to

123 OD600 of $0.59-0.64$ with Ringer's solution $1 / 4$ and used as inoculum for the following

124 experiments.

\section{Production of bacterial cellulose films}

126 Bacterial cellulose films were produced cultivating the bacterial strains in liquid

127 media in $150 \mathrm{~mm}$ diameter Petri dishes. $100 \mathrm{~mL}$ of HS liquid media were inoculated

128 with $250 \mu \mathrm{L}$ of the bacterial suspension and incubated at $30^{\circ} \mathrm{C}$ for 10 days in static

129 conditions. After growth, the produced films were soaked in $1 \% \mathrm{NaOH}$, incubated at 60

$130{ }^{\circ} \mathrm{C}$ for $2 \mathrm{~h}$ and washed with distilled water up to neutral $\mathrm{pH}$. Bacterial cellulose films

131 were dried at room temperature over Whatman filters.

\section{Composites and bilayers biomaterials}

$\mathrm{BC}$ was introduced in paper sheets by two different methods in order to obtain a composite or a bilayer. Two paper sheets were used in each case: commercial filter paper of $73 \mathrm{~g} \mathrm{~m}^{-2}$ (Filtros Anoia 1305) or laboratory made paper sheets of $75 \mathrm{~g} \mathrm{~m}^{-2}$ from 
136 Eucalyptus globulus TCF (totally chlorine free) bleached pulp, PFI refined at $45^{\circ} \mathrm{SR}$.

137 Eucalyptus pulp was supplied by ENCE (Pontevedra, Spain).

138 Composites of bacterial cellulose films and paper were produced growing the

139 bacterial strains on the surface of paper sheets layered on the top of solid media in 150

$140 \mathrm{~mm}$ diameter Petri dishes. $500 \mu \mathrm{L}$ of the bacterial suspension were mixed with $20 \mathrm{~mL}$ of

141 Ringer's solution $1 / 4$ and inoculated in $150 \mathrm{~mL}$ of HS solid media covered with paper

142 sheets and incubated at $30^{\circ} \mathrm{C}$ for 10 days under static conditions. After growth, the

143 composites of paper sheets and bacterial cellulose were removed, treated with $\mathrm{NaOH}$,

144 washed and dried as before at room temperature. Alternatively, they were also dried at

$14590^{\circ} \mathrm{C}$ for $5 \mathrm{~min}$.

146 In the bilayers, bacterial cellulose films, once washed, were layered over paper

147 sheets and the resulting coated sheets were dried at room temperature or at $90^{\circ} \mathrm{C}$ as

148 above mentioned. In this case, only the BC films from K. xylinus, were used.

\section{Paper characterization}

Physical-mechanical properties

151 They were determined in accordance with the standards in brackets as follows:

152 apparent density (ISO 534:2005), tensile strength index and elongation (ISO 1924-

153 2:1994), burst strength index (ISO 2758:2001), wet zero-span index (ISO 15361:2000)

154 and Bendtsen roughness (ISO 8791-2:2013).

155 Optical properties

156 Pulp brightness was determined according to ISO 2470-1. Specular Gloss was

157 determined according to ISO 8254-1:2009.

158 Barrier properties

159 Air permeance was measured with Bendtsen equipment (ISO 5636-5:2003).

160 Hydrophobicity was measured by the water contact angle (WCA) and water

161 impermeability by the water drop test (WDT). WCA was measured by using a

162 Dataphysics OCA15EC contact angle goniophotometer (Dataphysics, USA), using an

163 image capture ratio of 25 frames s$^{-1}$. Following the procedure described by Cusola et al.

1642014 a $4 \mu \mathrm{L}$ water drop was delivered to the sample surface. At least 8 measurements 
165 were made for each sample. Water drop test (WDT) was performed on each treated paper specimen according to Tappi standard T835 om-08. Previously the paper sheets were conditioned according to ISO 187. The WDT involved placing a drop of deionised water on the surface of paper and recording the time needed for complete absorption, which was signaled by vanishing of the drop specular gloss. Fifteen measurements per treated paper sample were made and averaged.

\section{Scanning electron microscopy (SEM)}

Surface and cross-sectional SEM pictures of the different films and biomaterials obtained were taken on a JEOL JSM-6400 microscope (Japan). Samples were placed on the SEM sample holding stub by means of conductive double side sticky carbon film and coated with $\mathrm{Au} / \mathrm{Pd}$ alloy prior to analysis.

\section{RESULTS}

\section{Bacterial cellulose films vs. papers from wood cellulose}

Several bacterial strains were tested for bacterial cellulose (BC) production on the HS standard medium. The screening includes several newly isolated and also culture collection strains. Two of them, Komagataeibacter xylinus and Gluconacetobacter sucrofermentans were selected as the best producers in the culture conditions assayed. The selected strains were grown for 10 days at $30^{\circ} \mathrm{C}$ in liquid media on Petri dishes of $15 \mathrm{~cm}$ diameter under static conditions. The bacterial growth produced surface cellulose films that were recovered and treated with $\mathrm{NaOH}$ to eliminate microbial cells, washed and dried at room temperature. Properties of the bacterial cellulose dried films obtained were analyzed and compared to those of commercial filter paper or of paper made from TCF eucalyptus pulp (Table 1). These two types of paper showed different properties in accordance to their different composition. Eucalyptus paper was smoother, had more density, higher physical properties and lower gloss than filter paper.

190 Moreover, it had better barrier properties to air and water. The properties of the BC

191 films produced by the two strains were quite similar and differed widely from those of

192 paper sheets. Although BC films had lower grammage than wood papers, their

193 mechanical properties were similar or even higher in some cases. This fact can be 
194 explained by the higher density of films made of BC, due to a better conformability of

195 BC fibers. In fact, Chen et al. (2017) reported similar density values of films from

196 nanofibrillated cellulose with high strength properties, but in that case the nanocellulose

197 was obtained from different plants (Chen et al. 2017).

199 Table 1. Physical, optical and barrier properties of bacterial cellulose films and papers from wood fibers, 200 filter paper $(\mathrm{Fp})$ and eucalyptus paper $(\mathrm{Eu})$

\begin{tabular}{|c|c|c|c|c|}
\hline & \multicolumn{2}{|c|}{ Bacterial cellulose films } & \multicolumn{2}{|c|}{ Papers from wood fibers } \\
\hline & K. Xylinus & G. sucroferm. & $\mathrm{Fp}$ & $\mathrm{Eu}$ \\
\hline Grammage $\left(\mathrm{g} \mathrm{m}^{-2}\right)$ & $10.7 \pm 2.1$ & $8.1 \pm 0.7$ & $71.4 \pm 1.4$ & $76.2 \pm 0.8$ \\
\hline Thickness $(\mu \mathrm{m})$ & $9.7 \pm 1.3$ & $9.3 \pm 1.3$ & $154 \pm 4.9$ & $115 \pm 1.0$ \\
\hline Apparent density $\left(\mathrm{g} \mathrm{cm}^{-3}\right)$ & $1.1 \pm 0.1$ & $0.9 \pm 0.1$ & $0.5 \pm 0.0$ & $0.7 \pm 0.0$ \\
\hline Tensile strength index $\left(\mathrm{N} \cdot \mathrm{m} \mathrm{g}^{-1}\right)$ & $18.1 \pm 5.2$ & $61.7 \pm 1.5$ & $34.0 \pm 3.2$ & $45.0 \pm 7.2$ \\
\hline Burst strength index $\left(\mathrm{kN} \mathrm{g}^{-1}\right)$ & $6.4 \pm 0.4$ & $1.2 \pm 0.9$ & $1.8 \pm 0.2$ & $3.0 \pm 0.1$ \\
\hline Elongation (\%) & $0.8 \pm 0.4$ & ND & $2.0 \pm 0.5$ & $2.7 \pm 0.2$ \\
\hline Wet Zero-Span index $\left(\mathrm{N} \cdot \mathrm{m} \mathrm{g}^{-1}\right)$ & $126 \pm 26$ & $114 \pm 4$ & $110 \pm 1$ & $106 \pm 3$ \\
\hline Gloss $(\%)^{*}$ & $31.0 \pm 6.0$ & $32.5 \pm 3.3$ & $17.0 \pm 0.3$ & $0.2 \pm 0.2$ \\
\hline Brightness $(\%)^{*}$ & $81.4 \pm 0.8$ & $82.5 \pm 0.7$ & $86.3 \pm 0.1$ & $85.0 \pm 0.6$ \\
\hline Bendtsen roughness $\left(\mathrm{mL} \min ^{-1}\right)^{*}$ & $24 \pm 9$ & $30 \pm 7$ & $1823 \pm 211$ & $993 \pm 54$ \\
\hline Bendtsen Air Permeance $\left(\mu \mathrm{m}(\mathrm{Pa} \cdot \mathrm{s})^{-1}\right)^{*}$ & $1.3 \pm 0.1$ & $1.1 \pm 0.5$ & $52.9 \pm 1.5$ & $7.4 \pm 1.3$ \\
\hline WDT $(\mathrm{s})^{*}$ & $4121 \pm 300$ & $4823 \pm 247$ & $1.7 \pm 0.3$ & $10.7 \pm 1.7$ \\
\hline $\mathrm{WCA}\left({ }^{\circ}\right)^{*}$ & $48.8 \pm 10.9$ & $38.6 \pm 0.8$ & $24.0 \pm 2.3$ & $33.8 \pm 7.0$ \\
\hline
\end{tabular}

$201 *$ Properties measured in the upper face

202

The more compact structure of BC provided dense films with a smoother surface

204 (lower Bendtsen roughness), and therefore higher gloss (Table 1). However, the most

205 remarkable difference with paper sheets was the strongly increased barrier properties to

206 air and water. Although air permeance was lower in eucalyptus paper than in filter

207 paper, it was significantly much lower in BC films. They also showed a remarkable

208 increased water drop test that raised from $10 \mathrm{~s}$ in eucalyptus paper to more than $4000 \mathrm{~s}$

209 in BC films. The water contact angle showed also higher values in BC films.

210 Comparing with other reports in which nanocellulose from plant cellulose was used, it

211 was found that nanocellulose provide lower air permeability (Syverud and Stenius 2009; 
212 Gicquel et al. 2017; Herrera et al. 2017) and similar values of WCA (Beltramino et al.

213 2015).

214 The results showed the high barrier properties of the films made of bacterial

215 cellulose. The high resistance to water absorption and to air penetration of the BC dried

216 films is an important trait that can be applied to enhance barrier properties of paper

217 sheets, especially in food packaging, in order to replace petrol-based packaging by

218 biodegradable products. For this reason, in order to provide these properties to final

219 papers products, two kinds of biomaterials were made combining BC and paper sheets:

220 composites and bilayer.

\section{$221 \quad$ Bacterial cellulose-paper composites}

\section{Mechanical and optical properties of composites}

223 To evaluate the contribution of $\mathrm{BC}$ to the properties of paper made from wood

224 pulp, composites of the two types of cellulose were made. For this purpose, the BC

225 producing strains were grown on the surface of paper sheets (filter or eucalyptus)

226 soaked on the top of solid media in $150 \mathrm{~mm}$ petri dishes. The paper sheets covered with

227 the bacterial growth were recovered and treated with alkali in the same conditions as

228 above. They were dried at room temperature or, alternatively, at $90{ }^{\circ} \mathrm{C}$ and their physical

229 properties analyzed (Table 2 ).

230 Table 2. Physical and optical properties of Composites made of filter (Fp) or eucalyptus (Eu) papers and 231 bacterial celluloses dried at room temperature

\begin{tabular}{|lcccc|}
\hline & \multicolumn{2}{c}{ Composite Fp } & \multicolumn{2}{c|}{ Composite Eu } \\
& K. xylinus & G. sucroferm & K. xylinus & G. sucroferm \\
Tensile strength index $\left(\mathrm{N} \cdot \mathrm{m} \mathrm{g}^{-1}\right)$ & $37.7 \pm 1.5$ & $39.5 \pm 0.5$ & $44.7 \pm 2.7$ & $46.5 \pm 1.7$ \\
Burst strength index $\left(\mathrm{kN} \mathrm{g}^{-1}\right)$ & $1.8 \pm 0.1$ & $2.3 \pm 0.4$ & $2.4 \pm 0.140$ & $2.7 \pm 0.4$ \\
Elongation (\%) & $1.8 \pm 0.1$ & $2.7 \pm 0.2$ & $2.2 \pm 0.2$ & $3.5 \pm 0.254$ \\
Wet Zero-Span index $\left(\mathrm{N} \cdot \mathrm{m} \mathrm{g}^{-1}\right)$ & $108 \pm 4$ & $101 \pm 22$ & $90 \pm 1$ & $75 \pm 6$ \\
Gloss (\%)* & $31.9 \pm 1.4$ & $31.5 \pm 3.8$ & $23.3 \pm 2.2$ & $22.9 \pm 1.6$ \\
Brightness (\%)* & $74.3 \pm 0.5$ & $79.0 \pm 0.3$ & $71.1 \pm 0.2$ & $79.2 \pm 0.3$ \\
Bendtsen roughness $\left(\mathrm{mL} \mathrm{min}^{-1}\right)^{*}$ & $1372 \pm 171$ & $1374 \pm 223$ & $945 \pm 50$ & $826 \pm 128$ \\
\hline
\end{tabular}

$232 *$ Properties measured in the upper face 

not significantly affected by the addition of BC. In general, mechanical properties of the

236 BC-paper composites showed similar values or a small increase than control paper

237 sheets (Table 1). This increase was slightly higher with G. sucrofermentans than with $K$. 238 xylinus.

Optical properties were determined on the upper face of the composites, that covered by the $\mathrm{BC}$ (Table 2). Gloss is an important property in the printing paper industry. Composites reached a notably higher gloss than their control samples, showing similar increased values with the two types of BC. Santos et al. (2017) reported that nonglossy papers can show a noticeable increment in their specular gloss when reinforced with $\mathrm{BC}$, in accordance with our results. Interestingly, a higher increase in gloss than in papers coated by cellulose nanocrystals from biomass (Gicquel et al. 2017) was obtained here with bacterial cellulose. Composites of filter paper showed also remarkable increase of whiteness (data not shown). Brightness determination revealed a decrease in this property in all composites. Composites with K. xylinus had the lowest brightness values.

\section{Barrier properties of composites}

The BC-paper composite sheets showed a notably lower wettability than the control paper sheets (Fig. 1), although not as low as the bacterial cellulose films (Table

253 1). WDT was determined on the two sides of the composites, the upper face, covered by

$254 \mathrm{BC}$, and the down face of the sheets. The WDT values of the upper face of the composites were remarkably higher in all samples (Fig. 1a). It was increased from 2-10

$256 \mathrm{~s}$ in control paper sheets not covered by $\mathrm{BC}$ to values ranging from 414 to $1220 \mathrm{~s}$ in the

257 BC-pulp composites. Down face of the composite sheets showed much lower increase

258 in water drop test values, indicating higher wettability of this face of the composites,

259 probably because the lack of bacterial cellulose penetration among pulp fibers in this

260 side. Regarding the influence of the drying temperature on the properties of the 261 composites, a detrimental effect of temperature was found, as water drop value of 262 samples dried at room temperature was approximately two times that of parallel samples 263 dried at $90{ }^{\circ} \mathrm{C}$. 
a)

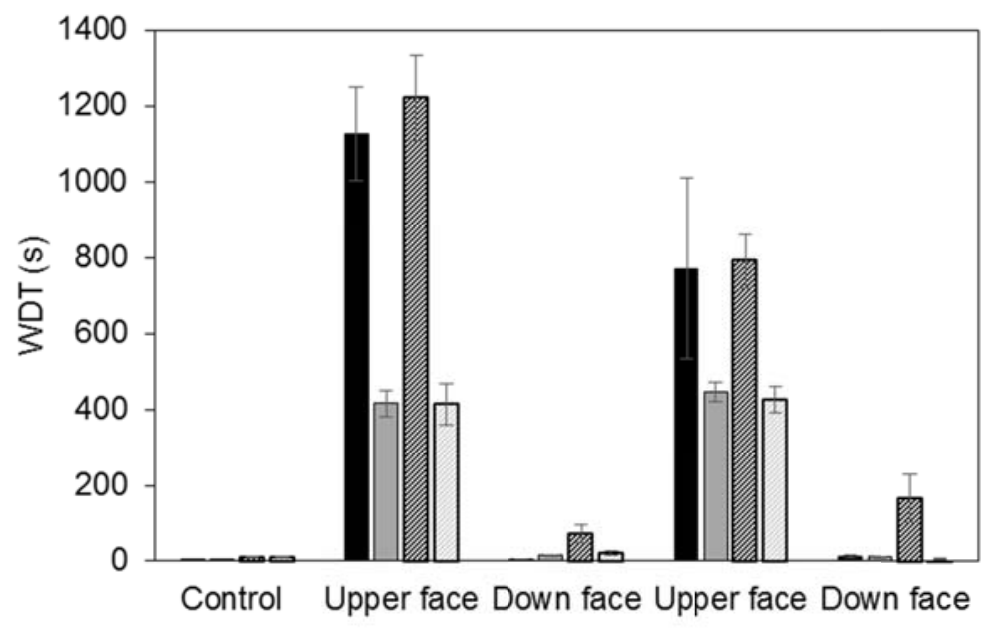

b)

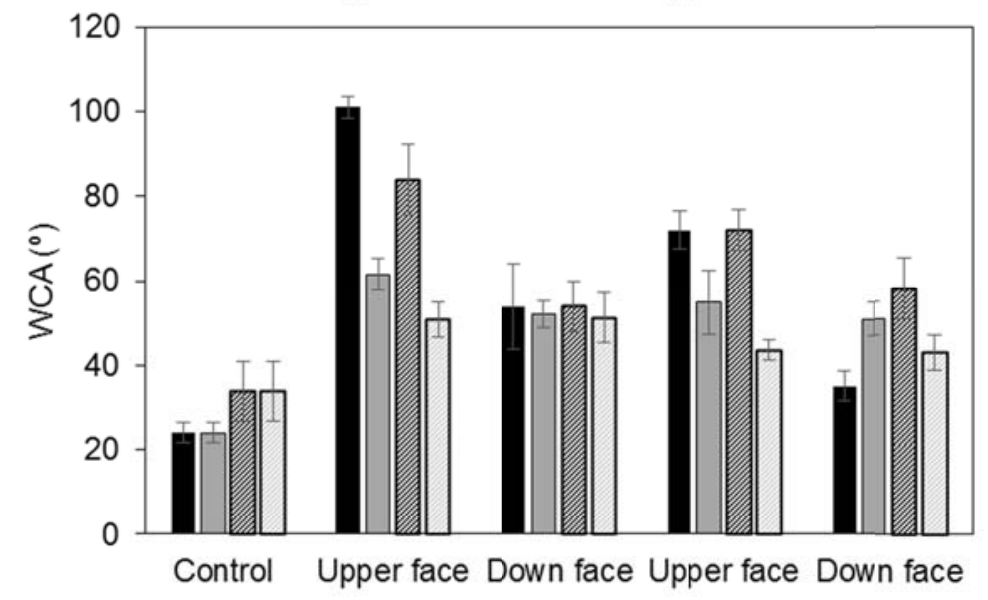

c)
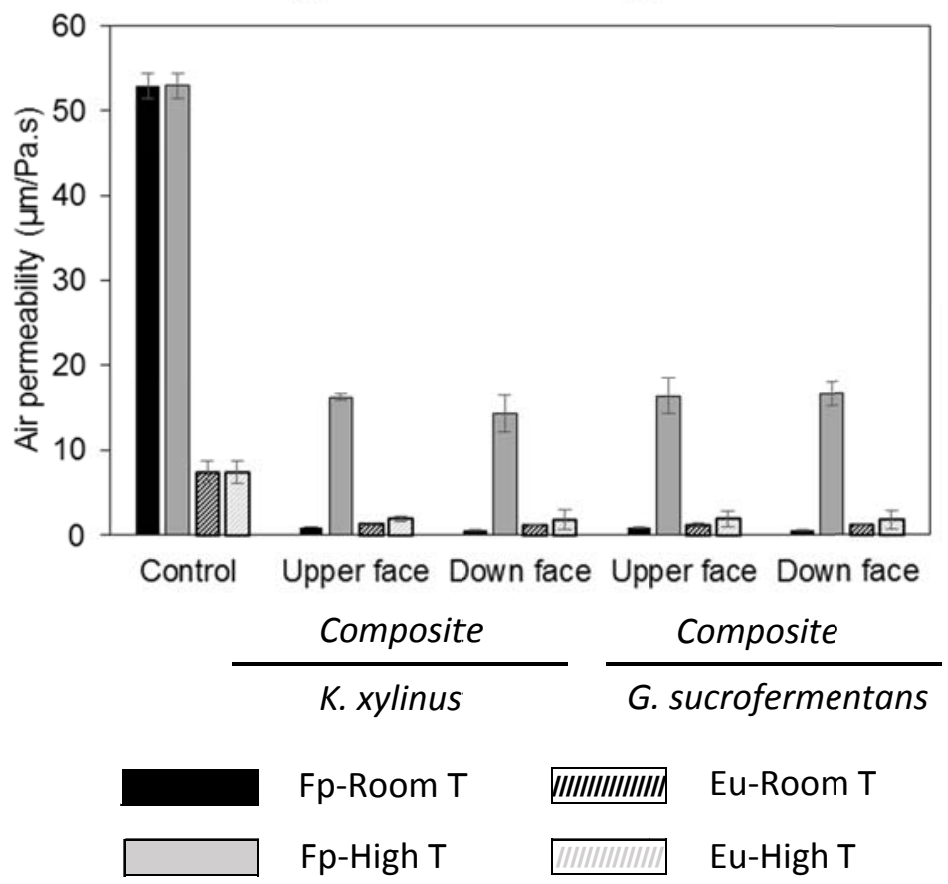

267 Fig. 1. Barrier properties to water of Composites made of filter (Fp) or eucalyptus papers (Eu) and 268 bacterial celluloses dried at room or high temperature. a) WDT; b) WCA; c) Air Permeability 
To evaluate the hydrophobicity of the composites, the water contact angle was also analyzed. The results showed an increased water contact angle of all composites,

270 that exhibited up to 3 fold increase compared with control paper sheets (Fig 1b).

271 Moreover, the differences between upper and down faces of the composites were

272 minimized. The drying temperature also influenced in water contact angle, with higher

273 results for the samples dried at room temperature.

The results found revealed that the composites of bacterial cellulose and paper sheets have a diminished capacity of water absorption, indicating an increased barrier property to water. To evaluate the barrier property to a different matter, air, the air permeability was analyzed. Composites containing filter paper showed a high decrease in permeability that diminished from the values corresponding to a high permeable control filter $(52.9 \mu \mathrm{m} / \mathrm{Pa} \cdot \mathrm{s})$ to a very closed paper $(0.53-0.94 \mu \mathrm{m} / \mathrm{Pa} \cdot \mathrm{s})$ when the composites were dried at room temperature. A lower effect was produced with eucalyptus sheets (from 7.4 to $1.11 \mu \mathrm{m} / \mathrm{Pa} \cdot \mathrm{s}$ ). Drying at high temperature gave also less permeable composites although permeability was decreased in lower extent, especially with filter paper. The lower air permeability was probably due to the small BC fragments filling the gaps between wood fibers and increasing the affinity between them. Controlling the permeability of substances through the packaging is also very important in food packaging in order to increase the shelf life of the product. In fact,

287 Tabarsa et al., 2017 also found a decrease in porosity combining BC and softwood 288 fibers, but mixing the fibers with BC before sheet formation.

\section{K. xylinus vs. G. sucrofermentans}

K. xylinus has been applied in previous works to increase the Young's modulus of composites made with cellulose acetate butyrate (Gindl and Keckes 2004) or with

292 phenolic resins (Nakagaito et al. 2005), or to modify the surface of natural fibers to

293 improve composite properties (Pommet et al. 2008). It has been also used to increase the 294 physical properties of papers resulting from mixing the BC with wood fibers (Gao et al. 295 2011; Tabarsa et al. 2017; Xiang et al. 2017a), but in a different manner as in the 296 present paper and with different results. However, fewer works have been reported with 297 G. sucrofermentans. A similar composite was performed by Santos et al. (2015, 2016a, 
b, 2017) in order to reinforce degraded papers. In this case, no variation in physical properties and a reduction of wettability was also found.

$300 \quad$ The results obtained in this research revealed that the two bacterial strains provided different properties in some cases. In contrast with the similar barrier

302 properties of the $\mathrm{BC}$ films of the two producing bacteria, composites containing $K$.

303 xylinus cellulose gave higher values of water barrier properties (Fig.1) than composites

304 with G. sucrofermentans cellulose (increase of up to $1100 \mathrm{~s}$ of WDT and $77^{\circ}$ the WCA

305 with the former vs. increase of $760 \mathrm{~s}$ WDT and $48^{\circ} \mathrm{WCA}$ with the latter in the case of

306 filter paper, and a similar behavior in eucalyptus paper). On the other hand, in both

307 paper supports, the two BC partners of the composites made a similar contribution to air

308 permeability, as similar values were found for K. xylinus and G. sucrofermentans

309 composites.

\section{Bacterial cellulose-paper bilayer}

Mechanical and optical properties of bilayer biomaterial

The BC-pulp composites analyzed were produced by the direct growth of the cellulose producing bacteria on the surface of paper sheets. The rational of this methodology was that the fibers of bacterial cellulose would probably grow intermixed among pulp fibers, making a compacted composite, which as we have shown, would exhibit an increased resistance to fluid penetration. The good results obtained made us to evaluate a different strategy to combine pulp and bacterial cellulose in a sheet. For this purpose, previously produced BC films were layered on paper sheets and the bilayer sheets were dried by the same procedure as above mentioned. We only used BC films from K. xylinus, which gave best results as previously shown. properties were not significantly affected in the bilayer material (Table 3). On the other hand, gloss was strongly increased, even more than in the composite. Brightness was decreased but in a lower extent than in the composite and roughness was strongly

326 decreased, especially in filter paper. A high smoothness is a required property in

327 printing applications and essential in printed electronics. It has been reported that other

328 kind of nanocelluloses from biomass applied on paper surface as coating treatment also 
329 provide some smoothness increase (Brodin et al. 2014; Gicquel et al. 2017; Herrera et 330 al. 2017).

331 Table 3. Physical and optical properties of Bilayers made of filter ( $\mathrm{Fp}$ ) or eucalyptus (Eu) papers and

332 bacterial cellulose from K. xylinus dried at room temperature

\begin{tabular}{|c|c|c|}
\hline & Bilayer Fp & Bilayer Eu \\
\hline Tensile strength index $\left(\mathrm{N} \cdot \mathrm{m} \mathrm{g}^{-1}\right)$ & $30.8 \pm 1.7$ & $39.4 \pm 1.6$ \\
\hline Burst strength index $\left(\mathrm{kN} \mathrm{g}^{-1}\right)$ & $2.0 \pm 0.0$ & $2.3 \pm 0.2$ \\
\hline Elongation (\%) & $1.9 \pm 1.6$ & $1.9 \pm 0.2$ \\
\hline Wet Zero-Span index $\left(\mathrm{N} \cdot \mathrm{m} \mathrm{g}^{-1}\right)$ & $95 \pm 4$ & $97 \pm 2$ \\
\hline Gloss $(\%)^{*}$ & $49.2 \pm 2$ & $46.4 \pm 0.4$ \\
\hline Brightness $(\%)^{*}$ & $80.0 \pm 1.0$ & $81.6 \pm 0.8$ \\
\hline Bendtsen roughness $\left.(\mathrm{mL} \mathrm{min})^{-1}\right)^{*}$ & $680 \pm 158$ & $517 \pm 41$ \\
\hline
\end{tabular}

* Properties measured in the upper face

The barrier properties of the bilayer sheets were determined on both sides (Fig. 2). Wettability of bilayer sheets was much lower than control paper sheets. Water drop test was again notably increased to values around 490 to $300 \mathrm{~s}$ in filter and eucalyptus papers, respectively. The values obtained were much lower than those of the corresponding BC-paper composites. No significant differences were obtained at room

340 or high temperature. Similar to that observed in the composites, no effect was produced

341 in the down face of the bilayer. In agreement with the water drop values, the water

342 contact angle of bilayer sheets was also increased in the upper face to $86^{\circ}$ and $44^{\circ}$ in

343 filter and eucalyptus papers, respectively. By contrast with that obtained with the WDT,

344 the water contact angle was increased in the down face of the bilayer made with filter 345 paper, although in a lower extent than in the upper face $\left(53^{\circ}\right)$. The temperature used for 346 drying, room or hot, did not make an important difference in wettability of bilayers, it 347 was only reduced in the upper face of filter paper. 
a)

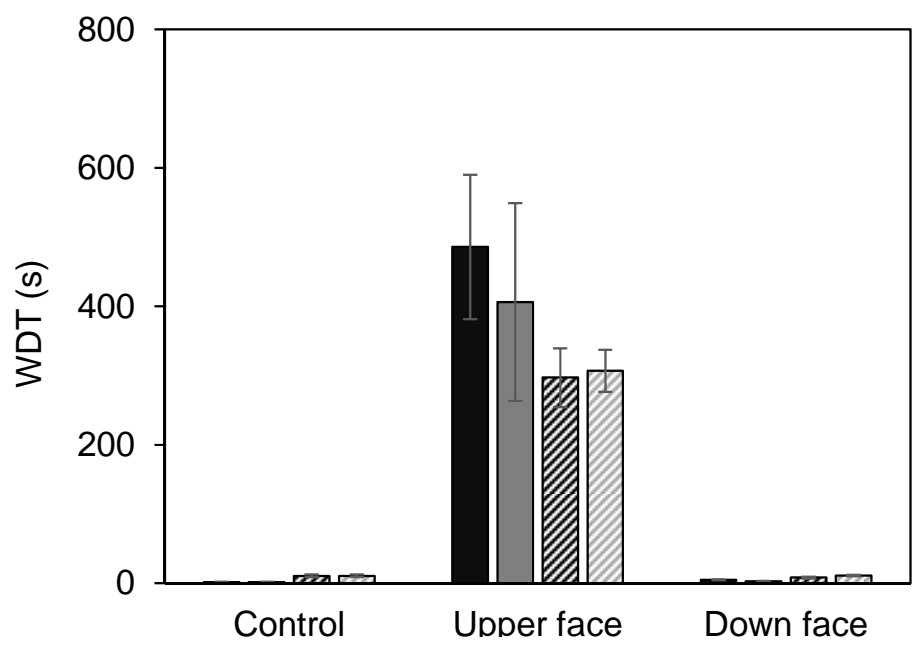

b)

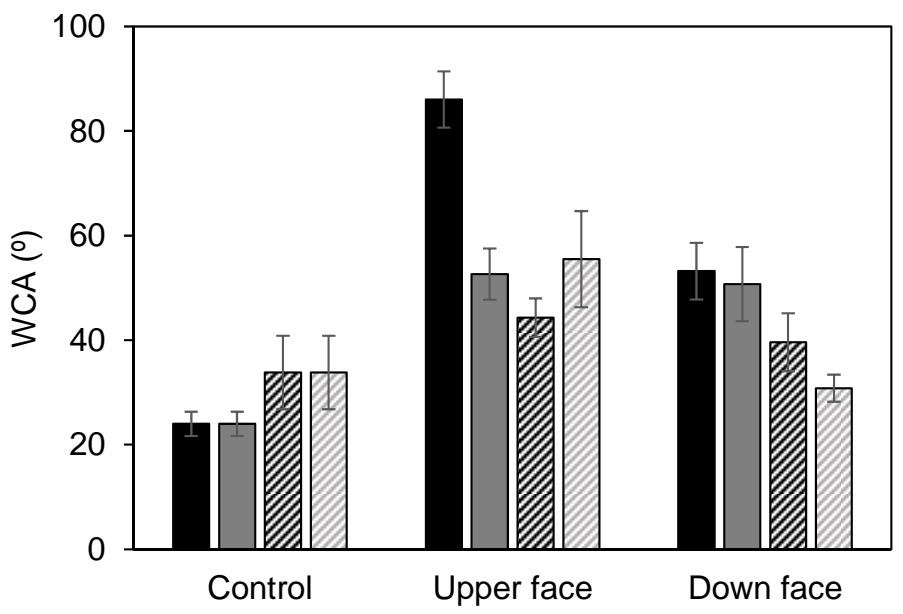

c)
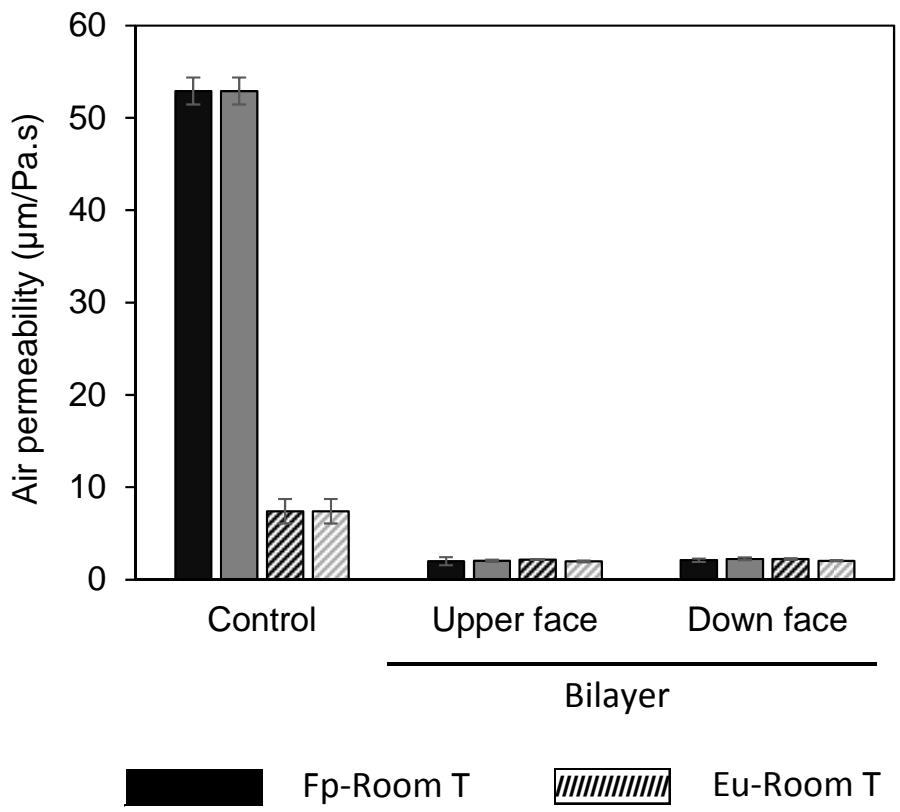

Fp-High T $\quad$ Eu-High T

350 Fig. 2. Barrier properties to water of Bilayer made of filter (Fp) or eucalyptus papers (Eu) and bacterial 351 cellulose from K. xylinus dried at room or high temperature. a) WDT; b) WCA; c) Air Permeability 
The barrier property to air, measured as air permeability, was strongly decreased

354 in the bilayer biomaterials, especially in the case of filter paper. Similarly to that found

355 in the composites no differences between the upper and lower face were observed, and

356 no effect of the drying temperature was produced.

357 Therefore, interesting results were found concerning the barrier properties to air

358 and water with paper and BC. Nanocelluloses from plants instead of bacteria have also

359 been used to improve these properties. Several authors (Syverud and Stenius 2009;

360 Aulin et al. 2010; Lavoine et al. 2014b) obtained a complete reduction of air

361 permeability when nanofibrillated cellulose was applied as a surface layer on paper

362 sheets. However Lavoine et al. 2014a found that nanofibrillated cellulose did not

363 increase the barrier property to water. Lower knowledge exists about the barrier

364 properties that cellulose nanocrystals coated on papers may provide. Recently, Gicquel

365 et al 2017 reported that papers coated with cellulose nanocrystals can strongly reduce its

366 air permeability maintaining the mechanical properties. One of the problems associated

367 with coating with this kind of nanocellulose is that the surface obtained is brittle and the

368 coat is split along the substrate fiber (Gicquel et al. 2017).

Composite vs. bilayer biomaterial

Two kinds of biomaterials (composite and bilayer) have been constructed combining wood fibers and bacterial cellulose produced by K. xylinus. Physical properties of papers were not adversely affected by the addition of bacterial cellulose in any case. Previous works (Gao et al. 2010; Tabarsa et al. 2017; Xiang et al. 2017a) reported an increase in physical properties in softwood or sugarcane bagasse fibers with K. xylinus. Some of these authors also stated that the amount of bacterial cellulose incorporated could affect the increases in physical properties. For example, Xiang et al. (2017a) specified that $\mathrm{BC}$ has to be introduced at low doses (lower than 1\%) whereas

378 Tabarsa et al.(2017) and Gao et al. (2010) found that physical properties of the sheets

379 increased with the bacterial cellulose dosage. According to the grammage increase (data

380 not shown), we determined that the amount of bacterial cellulose incorporated in our

381 biomaterials was around $15 \%$, which is similar to that used in these papers. An

382 explanation of the different behavior found may be explained by the way in which BC 
was introduced in vegetal fibers: in the previous works quoted, $\mathrm{BC}$ was disintegrated and mixed with fibers before sheet formation. Moreover, the wood fibers used in our work were refined, what probably made more difficult to increase the physical properties. In fact, Surma-Slusarska et al. (2008) also obtained a reduction in some physical properties when they combined BC and pine or birch fibers, obtaining a bilayer. Mechanical properties can also be increased by the addition of nanofibrillated cellulose as an additive in papermaking (Boufi et al. 2017).

Concerning brightness property, lower values were obtained in composites than in bilayer. This could be related with the highest roughness of composites structures. In fact, Gicquel et al. (2017) found that when the roughness increased, brightness decreased in their study in which paper samples were coated with nanocellulose. Moreover, Brodin et al. (2014) stated that the addition of nanofibrillated cellulose in the paper reduced the light scattering coefficient and the brightness of the sheets.

$\mathrm{BC}$ provided smoother surfaces with higher gloss in the upper face of both biomaterials. These properties were more improved in the bilayer biomaterial. Smoothness is an important factor that determines the good paper printability. However, barrier properties to water and air were much higher increased in composites. In the composite made with filter paper WDT and WCA increased up to $1120 \mathrm{~s}$ and $77^{\circ}$ with $\mathrm{BC}$ whereas these increases were $480 \mathrm{~s}$ and $62^{\circ}$ in the bilayer. Similarly, permeability was decreased $98 \%$ in the composite vs. $96 \%$ in the bilayer.

The temperature used for drying the biomaterials (room or $90^{\circ} \mathrm{C}$ ) had some influence on the final properties, that was different in the composites or bilayer materials. Whereas in the composites a detrimental effect in barrier properties was produced by drying at high temperature, no significant effect of temperature was produced in the bilayer materials. In both cases, the wettability was strongly reduced in the lower faces, because the lack of bacterial cellulose penetration among pulp fibers in this side, whereas the air permeability was not affected. The heterogeneous network structure of composite, formed by vegetal fibers (macro-material) and bacterial cellulose (nano-material) could be the reason of the different effect of temperature drying in final properties. Before the drying treatment, the composite has two wet materials with different size, and with different drying kinetics. According to the drying theory of porous materials, when the drying temperature is higher, the evaporation rate 
415 increases, that is, the drying kinetics is faster. Then the differences between the size and

416 the temperature during the drying treatment of the composite structure gives rise to a

417 different behavior of cellulosic fibers and bacterial cellulose, and therefore to a different

418 final dried structure.

419 The results show that the adhesion of bacterial cellulose films to the surface of

420 paper sheets in the bilayer gives rise to novel sheets with decreased wettability, and

421 decreased air permeability. However, the increase in barrier properties is much lower

422 than that obtained when bacterial cellulose and paper fibers are more intensely

423 interconnected in a composite.

424 Eucalyptus vs. filter paper

Values of barrier properties obtained in composites with each kind of paper support were very similar. However, the increases produced in each case were different.

427 The increase in WDT was similar in both paper types (1120 s vs. $1210 \mathrm{~s})$, whereas the

428 WCA increase was slightly higher in filter paper $\left(77^{\circ}\right.$ vs. $50^{\circ}$ in eucalyptus). Finally, the 429 air permeability decrease was also greater in filter paper (98\%) than in eucalyptus

$430(83 \%)$. These results suggest that the composition of the paper sheets used as support to 431 hold the bacterial growth gave also some influence.

432 In the bilayer biomaterial, a similar effect than in composites was produced. The 433 WDT and WCA increases were higher in filter paper $\left(480 \mathrm{~s}\right.$ and $\left.62^{\circ}\right)$ than in eucalyptus $434\left(290 \mathrm{~s}\right.$ and $\left.10^{\circ}\right)$. Determination of air permeability showed that bilayers made of 435 bacterial cellulose and filter paper exhibited a notable decrease of permeability $(96 \%)$,

436 while when the paper component of the bilayer was eucalyptus a lower effect was 437 produced (71\%). In fact, this effect may be explained by the lower initial barrier 438 properties of filter paper, what made it easier to improve them.

\section{Scanning Electron Microscope analysis}

$440 \quad$ Microscopic observation showed a different surface aspect of K. xylinus and $G$. 441 sucrofermentans BC films, although both of them are formed by a dense net of thin 442 cellulose fibers. Those of K. xylinus showed longer size fibers while G. sucrofermentans 443 films showed frequent short fibers. These differences may explain the different behavior 444 of bacterial cellulose in the composites, since barrier properties to water were more 

abundant and intensely connected at the surfaces, while they are more dispersed inside the films (Fig. 3a-c).

a)

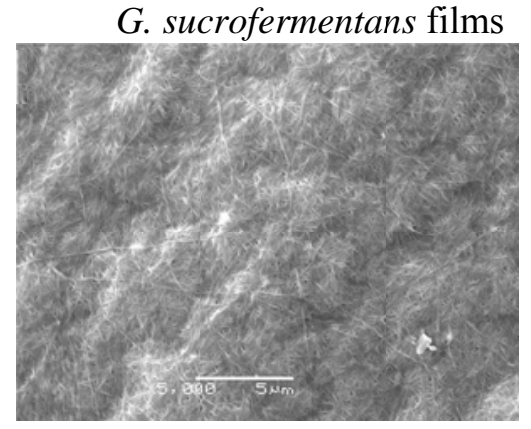

c)

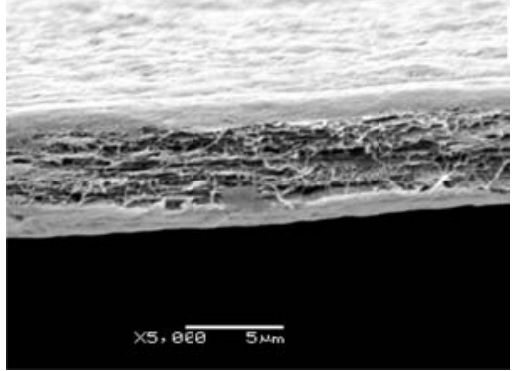

G. sucrofermentans films

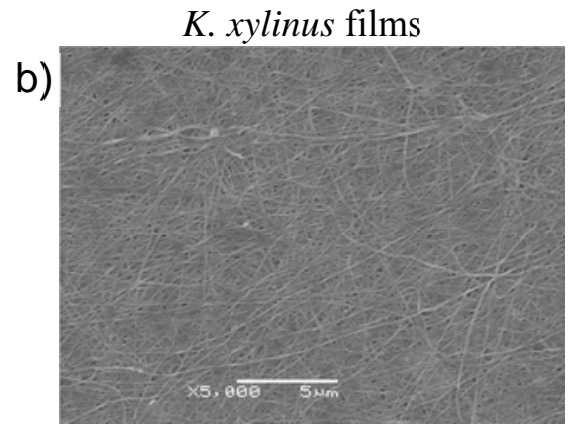

d)

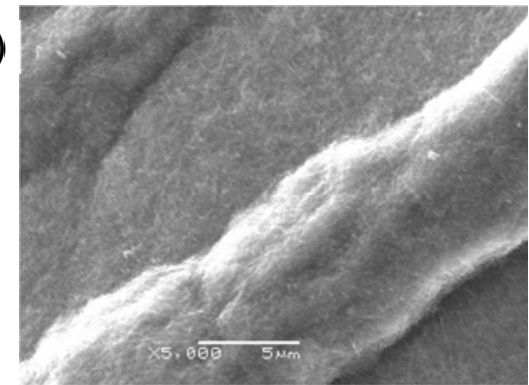

Composites

Filter paper / G. sucrofermentans

449

Fig. 3 SEM images of bacterial cellulose films from G. sucrofermentans (a, c) and K. xylinus (b). Composite of filter paper and G. sucrofermentans (d)

SEM analysis of BC-paper composites showed how the two types of cellulose fibers (bacterial and pulp) are interconnected. Paper fibers, of much thicker width, are covered by thin $\mathrm{BC}$ fibers making a compact material (Fig 3d). Analysis of composite surface shows it is covered by BC fibers that fill the space among pulp fibers making an apparently smooth and closed surface, in accordance with the increase in barrier properties found (Fig $4 \mathrm{a}, \mathrm{b}$ ). Cross section of the composites visualizes also the thin layer of BC fibers from G. sucrofermentans growing mainly on the surface of the composite (Fig 4c, d). A similar effect was found with the composite obtained from $K$. xylinus (Fig 4e, f). The low thickness of the BC layer on paper sheets justifies that thickness of composites or bilayers was not greatly modified. The images of composites show a compact structure, which made the surface of biomaterials more hydrophobic than the original paper surface. 
Control Filter Paper

a)

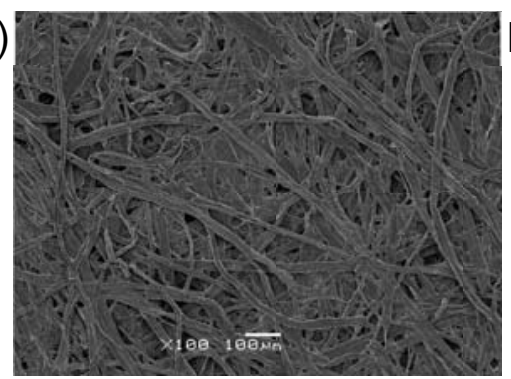

c)

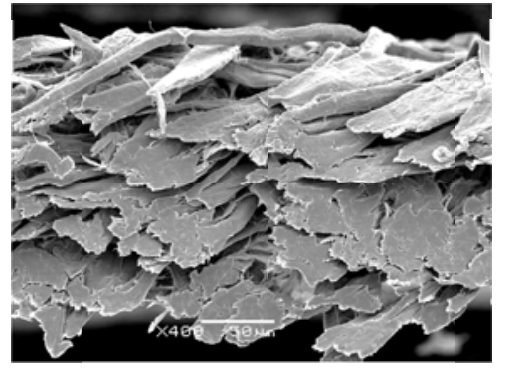

Composites

Filter Paper / G. sucrofermentans

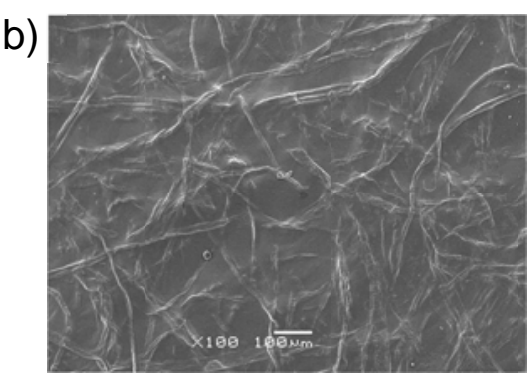

d)

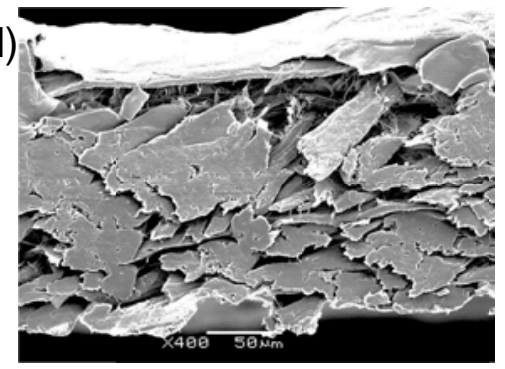

Composites

Filter Paper / K. xylinus

e)

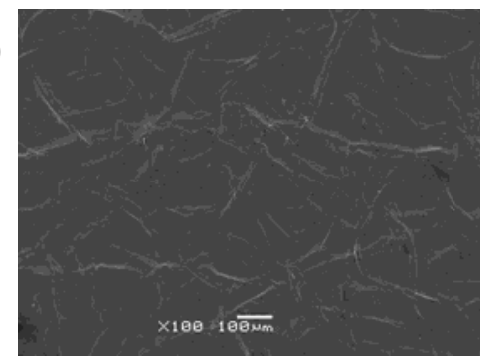

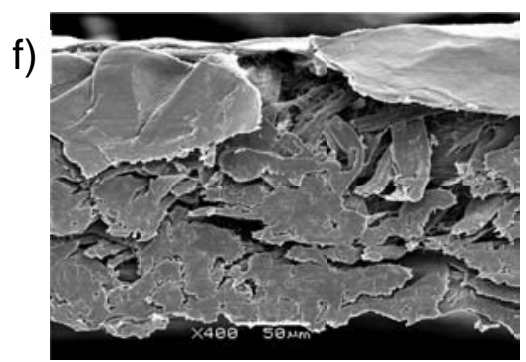

Fig. 4 SEM images of control filter paper (a, c); composite of filter paper and G. sucrofermentans (b, d); composite of filter paper and K. xylinus (e, f)

\section{Conclusions}

Hydrophobic and non-porous papers can be obtained combining wood cellulose

477 papers with a natural, biodegradable material: bacterial cellulose. Results show that this

478 effect depends on the bacterial strain used, on the kind of paper used and in the way BC

479 is incorporated into paper supports. Thus, BC from K. xylinus that presented longer size

480 fibers had stronger effect in reducing wettability of composites than G. sucrofermentans

481 that showed frequent short fibers. Barrier properties were more increased in filter paper,

482 probably due to its worse initial properties. Finally, although smoother surfaces with 
476 higher gloss can be obtained in the bilayer in comparison with the composite, BC-paper

477 fibers are more intensely connected in a composite, providing higher barrier properties

478 to air and water than in a bilayer biomaterial.

479

480 


\section{ACKNOWLEDGEMENTS}

482 The authors thank the "Ministerio de Economía y Competitividad" of Spain for their support in this

483 work under the projects FILMBIOCEL CTQ2016-77936-R (funding also from the "Fondo Europeo de

484 Desarrollo Regional FEDER”), BIOPAP $\mu$ FLUID (CTQ2013-48995-C2-1-R and CTQ2013-48995-C2-2-

485 R) and MICROBIOCEL (CTQ2017-84966-C2-1-R and CTQ2017-84966-C2-2-R). The authors are

486 grateful to the consolidated research UPC - UB group AGAUR 2017 SGR 30 and to the Serra Húnter

487 Fellow to Cristina Valls. The experiments described in this article have been performed complying with

488 the Spanish current laws.

489

490

491

492 


\section{REFERENCES}

494

Aulin C, Gällstedt M, Lindström T (2010) Oxygen and oil barrier properties of microfibrillated cellulose films and coatings. Cellulose 17:559-574 . doi: 10.1007/s10570-009-9393-y

Beltramino F, Roncero MB, Torres AL, et al (2016) Optimization of sulfuric acid hydrolysis conditions for preparation of nanocrystalline cellulose from enzymatically pretreated fibers. Cellulose 23:1777-1789 . doi: 10.1007/s10570-016-0897-y

Beltramino F, Roncero MB, Vidal T, et al (2015) Increasing yield of nanocrystalline cellulose preparation process by a cellulase pretreatment. Bioresour Technol 192:574-581 . doi: 10.1016/j.biortech.2015.06.007

Boufi S, González I, Delgado-Aguilar M, et al (2017) Nanofibrillated cellulose as an additive in papermaking process. Cellul Nanofibre Compos Prod Prop Appl 154:153-173 . doi: 10.1016/B9780-08-100957-4.00007-3

Brodin FW, Gregersen ØW, Syverud K (2014) Cellulose nanofibrils: Challenges and possibilities as a paper additive or coating material - A review. Nord Pulp Pap Res J 29:156-166 . doi: 10.3183/NPPRJ-2014-29-01-p156-166

Chawla PR, Bajaj IB, Survase S a., Singhal RS (2009) Microbial cellulose: Fermentative production and applications ( Review ). Food Technol Biotechnol 47:107-124

Chen Y, Geng B, Ru J, et al (2018) Comparative characteristics of TEMPO-oxidized cellulose nanofibers and resulting nanopapers from bamboo, softwood, and hardwood pulps. Cellulose 25:895 . doi: $10.1007 / \mathrm{s} 10570-017-1553-\mathrm{X}$

Cusola O, Valls C, Vidal T, Roncero MB (2014) Rapid functionalisation of cellulose-based materials using a mixture containing laccase activated lauryl gallate and sulfonated lignin. Holzforschung 68:631-639 . doi: 10.1515/hf-2013-0128

Gao W-H, Chen K-F, Yang R-D, et al (2010) Properties of Bacterial Cellulose and Its Influence on the Physical Properties of Paper. Bioresour Vol 6, No 1 6:144-153

Gicquel E, Martin C, Garrido Yanez J, Bras J (2017) Cellulose nanocrystals as new bio-based coating layer for improving fiber-based mechanical and barrier properties. J Mater Sci 52:3048-3061 . doi: $10.1007 / \mathrm{s} 10853-016-0589-\mathrm{x}$

Gilbert HJ (2010) The Biochemistry and Structural Biology of Plant Cell Wall Deconstruction. Plant Physiol 153:444-455 . doi: 10.1104/pp.110.156646

Hagiwara Y, Putra A, Kakugo A, et al (2010) Ligament-like tough double-network hydrogel based on bacterial cellulose. Cellulose 17:93-101 . doi: 10.1007/s10570-009-9357-2

Herrera MA, Mathew AP, Oksam K (2017) Barrier and mechanical properties of plasticized and crosslinked nanocellulose coatings for paper packaging applications. Cellulose 24:3969-3980. doi: 10.1007/s10570-017-1405-8

Klemm D, Heublein B, Fink HP, Bohn A (2005) Cellulose: Fascinating biopolymer and sustainable raw material. Angew Chemie - Int Ed 44:3358-3393 . doi: 10.1002/anie.200460587 
530 Klemm D, Kramer F, Moritz S, et al (2011) Nanocelluloses: A new family of nature-based materials.

$531 \quad$ Angew Chemie - Int Ed 50:5438-5466 . doi: 10.1002/anie.201001273

532 Lavoine N, Bras J, Desloges I (2014a) Mechanical and Barrier Properties of Cardboard and 3D Packaging

533 Coated with Microfibrillated Cellulose. J Appl Polym Sci 40106:1-11 . doi: 10.1002/app.40106

534 Lavoine N, Desloges I, Khelifi B, Bras J (2014b) Impact of different coating processes of microfibrillated

535 cellulose on the mechanical and barrier properties of paper. J Mater Sci 49:2879-2893 . doi:

$536 \quad 10.1007 / \mathrm{s} 10853-013-7995-0$

537

Lim GH, Lee J, Kwon N, et al (2016) Fabrication of flexible magnetic papers based on bacterial cellulose and barium hexaferrite with improved mechanical properties. Electron Mater Lett 12:574-579 . doi: 10.1007/s13391-016-6179-x

Lin SP, Loira Calvar I, Catchmark JM, et al (2013) Biosynthesis, production and applications of bacterial cellulose. Cellulose 20:2191-2219 . doi: 10.1007/s10570-013-9994-3

Osong SH, Norgren S, Engstrand P (2016) Processing of wood-based microfibrillated cellulose and nanofibrillated cellulose, and applications relating to papermaking: a review. Cellulose 23:93-123 . doi: 10.1007/s10570-015-0798-5

Pommet M, Juntaro J, Heng JYY, et al (2008) Surface modification of natural fibers using bacteria: Depositing bacterial cellulose onto natural fibers to create hierarchical fiber reinforced nanocomposites. Biomacromolecules 9:1643-1651 . doi: 10.1021/bm800169g

Quintana E, Valls C, Vidal T, Blanca Roncero M (2013) An enzyme-catalysed bleaching treatment to meet dissolving pulp characteristics for cellulose derivatives applications. Bioresour Technol 148:1-8 . doi: 10.1016/j.biortech.2013.08.104

Quintana E, Valls C, Vidal T, Roncero MB (2015) Comparative evaluation of the action of two different endoglucanases. Part I: On a fully bleached, commercial acid sulfite dissolving pulp. Cellulose 22:2067-2079 . doi: 10.1007/s10570-015-0623-1

Santos SM, Carbajo JM, Gómez N, et al (2016a) Use of bacterial cellulose in degraded paper restoration. Part I: application on model papers. J Mater Sci 51:1541-1552 . doi: 10.1007/s10853-015-9477-z

Santos SM, Carbajo JM, Gómez N, et al (2016b) Use of bacterial cellulose in degraded paper restoration. Part II: application on real samples. J Mater Sci 51:1553-1561 . doi: 10.1007/s10853-015-9477-z

Santos SM, Carbajo JM, Gómez N, et al (2017) Paper reinforcing by in situ growth of bacterial cellulose. J Mater Sci 52:5882-5893 . doi: 10.1007/s10853-017-0824-0 on its use on paper restoration. Carbohydr Polym 116:173-181 . doi: 10.1016/j.carbpol.2014.03.064 multipurpose advanced material. Carbohydr Polym 98:1585-1598 . doi: 10.1016/j.carbpol.2013.08.018 Pine Sulphate Pulps with Bacterial Cellulose. Fibres Text East Eur 16:127-129 
Tabarsa T, Sheykhnazari S, Ashori A, Mashkour M (2017) Preparation and characterization of reinforced

570

571

572

573

574

575

576

577

578

579

580

581

582

583

584

585

586

587 papers using nano bacterial cellulose. Int J Biol Macromol 101:334-340 . doi: 10.1016/j.ijbiomac.2017.03.108

Tang L, Huang B, Lu Q, et al (2013) Ultrasonication-assisted manufacture of cellulose nanocrystals esterified with acetic acid. Bioresour Technol 127:100-105 . doi: 10.1016/j.biortech.2012.09.133

Tuck CO, Pérez E, Horváth IT, et al (2012) Valorization of Biomass : Deriving More Value from Waste. Science (80- ) 337:695-699

Wu SQ, Li MY, Fang BS, Tong H (2012) Reinforcement of vulnerable historic silk fabrics with bacterial cellulose film and its light aging behavior. Carbohydr Polym 88:496-501 . doi:

10.1016/j.carbpol.2011.12.033

Xiang Z, Jin X, Quingguo L, et al (2017a) The reinforcement mechanism of bacterial cellulose on paper made from woody and non-woody fiber sources. Cellulose 24:5147-5156 . doi: 10.1007/s10570017-1468-6

Xiang Z, Liu Q, Chen Y, Lu F (2017b) Effects of physical and chemical structures of bacterial cellulose on its enhancement to paper physical properties. Cellulose 24:3513-3523 . doi: 10.1007/s10570017-1361-3

Yamanaka S, Watanabe K, Kitamura N, et al (1989) The Structure and Mechanical-Properties of Sheets Prepared from Bacterial Cellulose. J Mater Sci 24:3141-3145 . doi: Doi 10.1007/Bf01139032 